\title{
A Novel Supply System for Two-Phase Induction Motor by Single Leg Matrix Converter
}

\author{
Branislav Dobrucky ${ }^{1}$, Tomas Laskody ${ }^{1}$, Michal Prazenica ${ }^{1}$ \\ University of Zilina, Faculty of Electrical Engineering, \\ Univerzitna 1, 01026 Zilina, Slovakia \\ branislav.dobrucky@fel.uniza.sk
}

\begin{abstract}
The paper deals with the novel supply system for two phase induction motor. The system comprises just single leg of matrix converter, and features by reduced number of active and passive components of the supply unit. In comparison to VSI one-leg inverters with rather bulky smoothing capacitors, direct matrix converters operate without DC-link circuit. Analysis using computer simulation under both passive $R-L$ and motoric load is given in the paper.
\end{abstract}

Index Terms-Bidirectional switch, induction motor, twophase system, single leg, matrix converter, power semiconductor devices.

\section{INTRODUCTION}

The matrix converter topology has become well known after substitution of thyristor-devices in cycloconverters by switched-off elements acting in high frequency range, in 70s-80s-years [1]-[3], [16]. Matrix converter replace two energy conversion to only one energy conversion, because within converter is not any energy storage element. Classical electric conversion uses DC link converters with rather bulky smoothing capacitors, since direct matrix converters operate without of DC-link circuit. One of the main advantages of that is unity power factor on its input side. Another advantage is that this converter offers sinusoidal input and output harmonic quantity and bi-directional energy flow [3], [8].

Two phase induction motor can be supplied either from two single phase converters or one three-phase VSI inverter [9]-[10], [14]. Another way is using of two matrix converters in half-bridge connection [5]-[7]. Thanks to absence of any energy storage element, the instantaneous power on input must be the same as the power on output side. Unfortunately reactive power input does not have to equal the reactive power output. In $\mathrm{MxC}$ it is possible to control the phase angle between the voltages and current on the input - the output phase angle differs from input phase. Another advantage is that the forms of waveforms at the two sides are independent. So the input could be two-phase AC and output DC, or both could be DC, or both could be AC. To save the number power switching elements is also possible to use one-leg connection of the converter [11]-

Manuscript received February 4, 2015; accepted May 15, 2015.

This research was funded by a grant VEGA No. 1/0928/15.
[13], [20].The proposed system, in comparison with the conventional system currently used [11]-[13] reduces of the number power switching elements of the converter.

\section{Single LEG MAtrix CONVERTER DESCRIPTION}

A single phase matrix converter in basic bridge connection is created by four bidirectional switches (BiS), which allow power flow through the converter from both sides. The basic scheme of half-bridge single-phase matrix converter created by two bi-switches and $\mathrm{AC}$ voltage divider is shown in Fig. 1(a), Fig. 1(b)
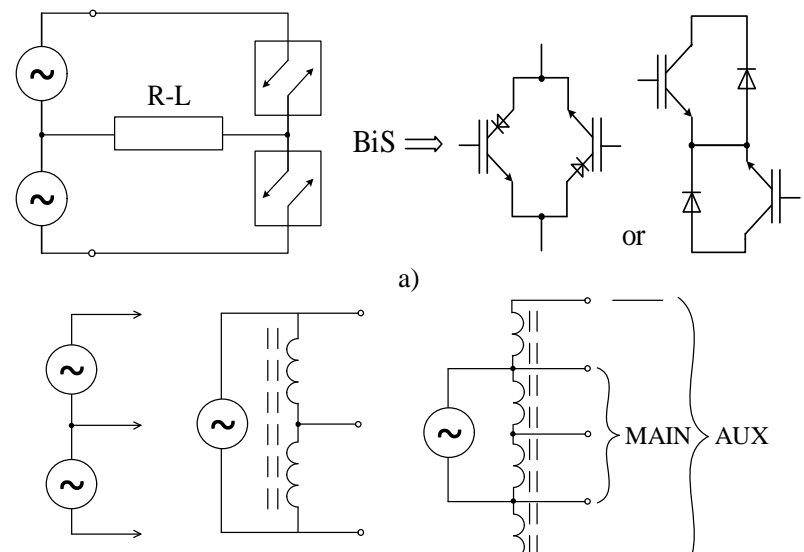

a)

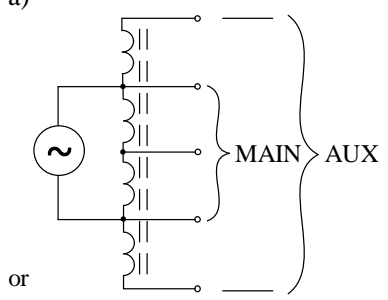

b)

Fig. 1. Basic scheme of half bridge MxC converter (a) with bidirectional switch; inductive divider or autotransformer (b).

The matrix converter requires special semiconductor switches. The matrix converter requires a bidirectional switch, capable of blocking voltage and conducting current in both directions the energy flow can get from source to load and back. These bidirectional switches, consisting of a pair of devices with turn-off capability, can be reverse blocking RB_IGBTs or more usually IGBTs with antiparallel diodes, connected in either a common collector or a common emitter back-to-back arrangement [2]-[3], [5].

The relation between output and input voltages of matrix converter is as follows [3], [7], [8]

$$
\left[v_{o}(t)\right]=[M(t)]\left[v_{i}(t)\right]
$$

where $v_{i}(t)$ and $v_{o}(t)$ are input- and output voltages, 
respectively; $M(t)$ is modulation matrix

$$
[M(t)]=\left[\begin{array}{ll}
m_{a A}(t) & m_{a B}(t) \\
m_{b A}(t) & m_{b B}(t)
\end{array}\right],
$$

where $m_{a A}(t), m_{a B}(t), m_{b A}(t), m_{b B}(t)$ are modulation indexes (time of switched state $t_{\mathrm{xx}} / T_{\mathrm{seq}}$ ) with respect to prevent short circuit.

Reciprocally it is valid:

$$
\begin{array}{r}
{\left[v_{i}(t)\right]=[M(t)]^{T}\left[v_{o}(t)\right],} \\
{\left[i_{i}(t)\right]=[M(t)]^{T}\left[i_{o}(t)\right],}
\end{array}
$$

where $[M(t)]^{T}$ is transposed matrix.

Principal schematics of single-leg matrix converter (SL_MxC) supplying two phase induction motor are depicted in Fig. 2 and Fig. 3.

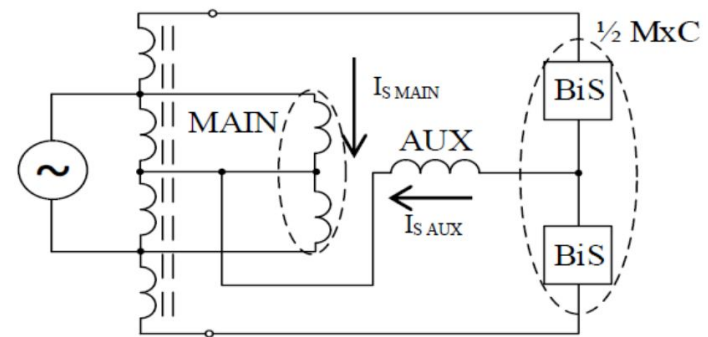

Fig. 2. Schematics of SL_MxC in full speed operation $(50 \mathrm{~Hz})$.

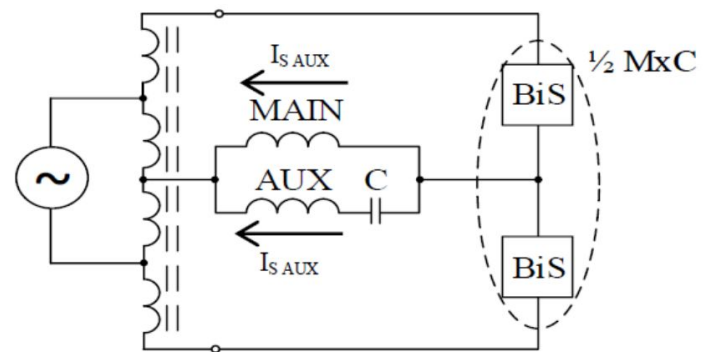

Fig. 3. Schematics of SL_MxC in reduced speed operation $(10 \mathrm{~Hz}-49 \mathrm{~Hz})$.

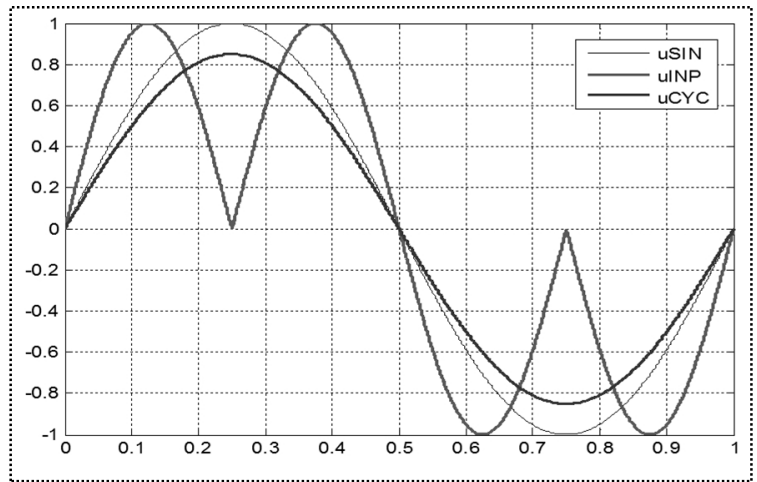

Fig. 4. Two-pulse direct converter fundamental harmonic reaching $0.85 \%$ of the main voltage (x: time [n*T]; y: g-input voltage; b-reference; $r$ fundamental harmonic).

In full speed regime of operation the main phase of IM is supplied by one half of the main voltage directly; therefore motor should be designed for that voltage. The auxiliary phase is supplied by one-leg matrix converter creating voltage with phase shift by 90 degrees against voltage of the main phase. Using sinusoidal PWM modulation is possible to obtain fundamental harmonic with maximal value lesser than main voltage fundamental [5], [16]. Principle of obtaining of fundamental harmonic is shown in Fig. 4.

Example of calculation fundamental harmonic for half speed $(25 \mathrm{~Hz})$ using Fourier analysis with following integration [4]

$$
\begin{gathered}
U_{2 \max (1 \cdot \text { HARM })}=\frac{8}{T} \int_{0}^{T / 4} \cos (2 \omega t) \cdot \cos (\omega t) d t= \\
=\frac{8}{T} \int_{0}^{T / 4} \frac{1}{2}[\cos (\omega t)-\cos (3 \omega t)] d t= \\
=\frac{4}{T}\left\{\frac{1}{\omega}[\sin (\omega t)]_{0}^{\frac{T}{4}}-\frac{1}{3 \omega}\left[\sin (3 \omega t)_{0}^{\frac{T}{4}}\right]\right\}= \\
=\frac{4}{T \omega}\left\{\left[\sin \left(\omega \frac{T}{4}\right)-\sin (0)\right]-\frac{1}{3}\left[\sin \left(3 \omega \frac{T}{4}\right)-\sin (0)\right]\right\}= \\
=\frac{2}{\pi}\left[(1-0)-\frac{1}{3}(-1-0)\right]=\frac{2}{\pi}\left(1+\frac{1}{3}\right)=\frac{2}{\pi}\left(1+\frac{1}{3}\right)= \\
=\frac{2}{\pi} \times \frac{4}{3} \approx 0.85 \Rightarrow 85 \% .
\end{gathered}
$$

This value is varied in full range of the speed from 0.85 to 0.82 . Thus, the RMS value of the output voltage of the oneleg converter should be $(1.15 \div 1.18)$ times greater than requested voltage of the main phase of the system.

In the reduced speed regime of operation both the mainand auxiliary phases of IM are supplied by one-leg of matrix converter; the main one directly; the auxiliary through the capacitor which provides phase shift 90 degrees.

\section{Single LEG MATRIX CONVERTER OPERATION}

Single Leg Matrix Converter is dedicated for supplying of two phase induction motor. Model of such a motor is known [13]-[15], [17]-[19]. So, the electric machine being considered may be described by the following set of ordinary differential equations in the stator reference coordinate frame under the commonly used simplifying assumptions:

$$
\begin{aligned}
u_{s \alpha}= & R_{s \alpha} i_{s \alpha}+L_{s \alpha} \frac{\mathrm{d} i_{s \alpha}}{\mathrm{d} t}+L_{M \alpha} \frac{\mathrm{d} i_{r \alpha}}{\mathrm{d} t}, \\
u_{s \beta}= & R_{s \beta} i_{s \beta}+L_{s \beta} \frac{\mathrm{d} i_{s \beta}}{\mathrm{d} t}+L_{M \beta} \frac{\mathrm{d} i_{r \beta}}{\mathrm{d} t}, \\
0= & R_{r \alpha} i_{r \alpha}+L_{s \alpha} \frac{\mathrm{d} i_{r \alpha}}{\mathrm{d} t}+L_{M \alpha} \frac{\mathrm{d} i_{s \alpha}}{\mathrm{d} t}+ \\
& +\frac{1}{N} \omega_{m}\left(L_{r \beta} i_{r \beta}+L_{M \beta} i_{s \beta}\right), \\
0= & R_{r \beta} i_{r \beta}+L_{r \beta} \frac{\mathrm{d} i_{r \beta}}{\mathrm{d} t}+L_{M \beta} \frac{\mathrm{d} i_{s \beta}}{\mathrm{d} t}- \\
& -N \omega_{m}\left(L_{r \alpha} i_{r \alpha}+L_{M \alpha} i_{s \alpha}\right), \\
T_{e}= & p p\left[N\left(L_{r \alpha} i_{r \alpha}+L_{M \alpha} i_{s \alpha}\right) i_{r \beta}-\right. \\
& \left.-\frac{1}{N}\left(L_{r \beta} i_{r \beta}+L_{M \beta} i_{s \beta}\right) i_{r \alpha}\right],
\end{aligned}
$$




$$
T_{e}=T_{\text {load }}+J \frac{\mathrm{d} \omega_{m}}{\mathrm{~d} t}
$$

where $N$ is the ratio between the effective numbers of turns in the auxiliary and the main stator windings; $\omega_{m}-$ mechanical angular speed, and $p p$ - is the number of pole pairs. Stator voltages $u_{s \alpha}$ and $u_{s \beta}$ of main and auxiliary windings are presented in Fig. 5 in full speed, and reduced speed operation.
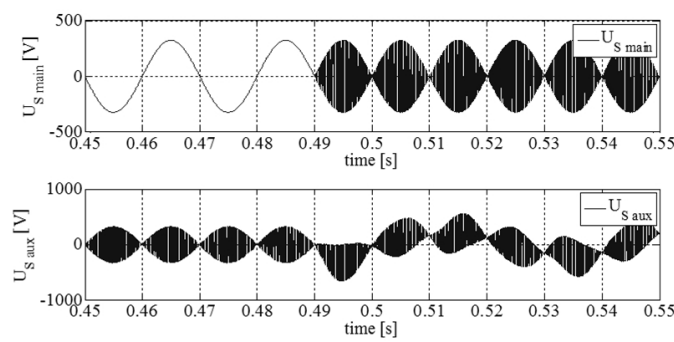

Fig. 5. Creating main and auxiliary voltages of SL_MxC in full speed $50 \mathrm{~Hz}$ (a), and reduced speed $25 \mathrm{~Hz}$ operation (b).

Stability of the system is provides by current feed-back with hysteresis controller. Referenced current corresponds to the mechanical load. Speed feed-back loop is not used, so far. As a main problem is to estimate and provide the optimal value of capacitance of the run capacitor to be put in series with the auxiliary winding. Its value can be calculated by one or more methods [13], [18], [21], [22], e.g: using the double revolving field theory, and others. Practical solution leads to switched capacitors. One of the best ways to change the capacitance is to introduce the PWM-controlled choppers between the capacitors. Using these choppers, the capacitors can be switched on and off respectively thus supporting minimal switching losses.

\section{Simulation OF SL_MxC Under R-L LOAD}

The analysis of matrix converter is simulated using the Matlab-Simulink package. All simulations were calculated for source voltage $230 \mathrm{~V}, 50 \mathrm{~Hz}$, load resistance $R=64 \Omega$, load inductance $L=0.001 \mathrm{H}$. Current waveforms are shown in Fig. 6 without- and Fig. 7 with capacitor $C=8 \mu F$.

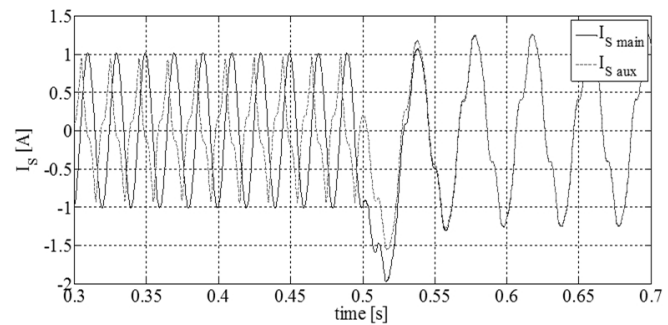

Fig. 6. Stator currents of main and auxiliary phases at $50 \mathrm{~Hz}$ and $25 \mathrm{~Hz}$ without $\mathrm{C}$ in auxiliary phase.

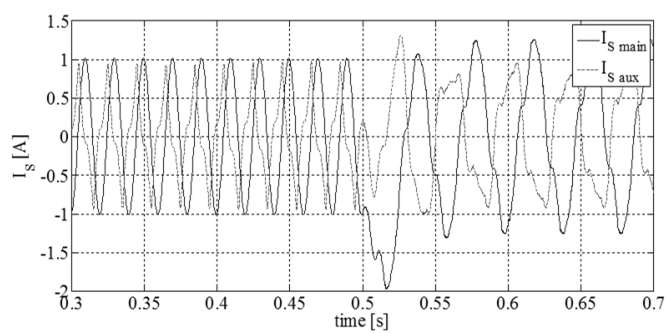

Fig. 7. Stator currents of main and auxiliary phases at $50 \mathrm{~Hz}$ and $25 \mathrm{~Hz}$ with $\mathrm{C}$ in auxiliary phase.
Time waveforms of main and auxiliary phase currents are corresponded to the voltage waveforms at $50 \mathrm{~Hz}$ and $25 \mathrm{~Hz}$ shown in Fig. 5(a) and Fig. 5(b).

\section{Simulation OF SL_MXC LOADED By IM MotoR}

\section{A. Parameters of the Simulations}

All simulations were calculated using the MatlabSimulink package for source voltage $230 \mathrm{~V}, 50 \mathrm{~Hz}$, at calculation step of $10 \mu \mathrm{sec}$.

Parameters of the two phase motor:

Stator voltage $115 \mathrm{~V}$

Stator resistance $\quad R_{s \alpha}=58.85 \Omega ; \quad R_{s \beta}=66.1 \Omega$; $R_{r}=80 \Omega$;

Stator inductance $L_{s d}=1.835 \mathrm{H} ; L_{s q}=1.64 \mathrm{H}$;

Mutual inductance between rotor and stator $M_{\text {srd }}=1.74 \mathrm{H} ; M_{\text {srq }}=1.52 \mathrm{H}$;

Moment of inertia $J=0.0000488 \mathrm{~kg} . \mathrm{m}^{2}$;

Number of pole pairs $p p=1$;

Capacitance of the capacitor in auxiliary phase $C=8 \mu F$.

\section{B. Simulation Results at Full and Reduced Speed of the Motor}

The motor is started-up onto nominal speed. At time instant of $0.5 \mathrm{sec}$ is done step change of frequency from $50 \mathrm{~Hz}$ to $25 \mathrm{~Hz}$. At time instant of $1 \mathrm{sec}$ is done step change of the load from 0 N.m to 0.1 N.m.

Stator current waveforms of main and auxiliary phases at $50 \mathrm{~Hz}$ and $25 \mathrm{~Hz}$ are depicted in Fig. 8.

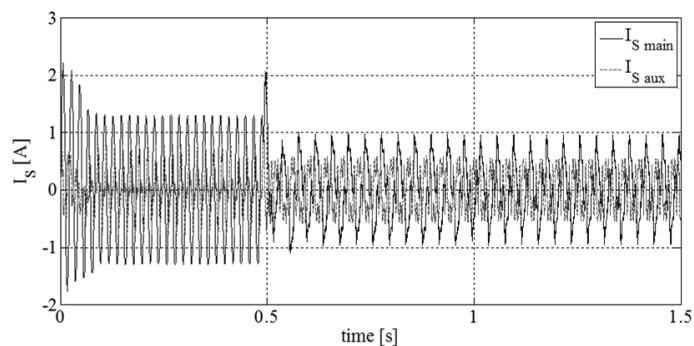

Fig. 8. Stator currents of main and auxiliary winding in full speed (a) and reduced speed regime.

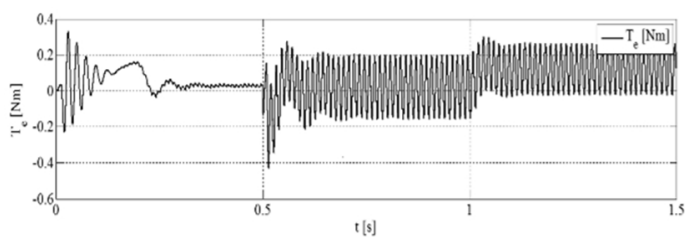

Fig. 9. Electromagnetic torque of the motor in full speed and reduced speed regimes.

Time waveforms of main and auxiliary phases in full- and reduced speed regimes of operation are corresponded to the voltage waveforms at $50 \mathrm{~Hz}$ and $25 \mathrm{~Hz}$ shown in Fig. 5(a) and Fig. 5(b).

Electromagnetic torque of the motor in full speed $(50 \mathrm{~Hz})$ and at reduced speed $(40 \mathrm{~Hz})$ regimes is shown in Fig. 9.

The torque of the capacitor-run two-phase IM depends on the currents in both the main and the auxiliary windings. Along with the frequency decrease, an impedance of the auxiliary winding grows because of the series-connected capacitor, which reactance is inversely proportional to the 
frequency. At the same time, an impedance of the main winding decreases at low frequencies. An effect of electromagnetic torque lowering along with the frequency drop can be explained using the torque equilibrium (8), [22].

Angular speed of the motor in full speed $50 \mathrm{~Hz}$ and reduced speed $25 \mathrm{~Hz}$ regimes is presented in Fig. 10.

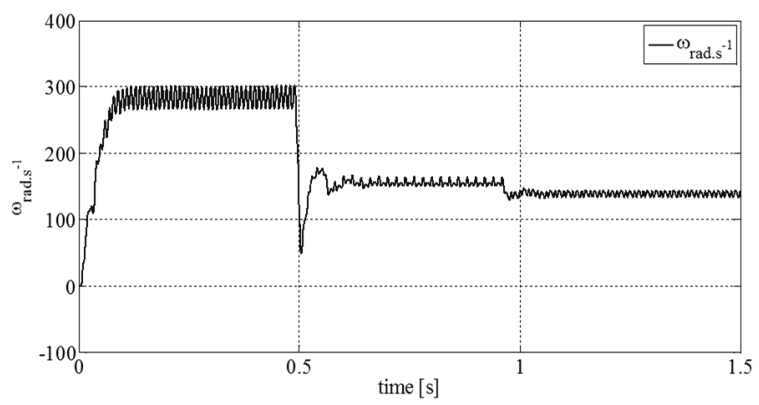

Fig. 10. Angular speed of the motor in full speed and reduced speed regimes.

\section{Discussion to Simulation Results under R-L and Motoric Loads}

Above worked-out results under R-L and motoric loads are just preliminary ones because of value of capacitance of the capacitor in auxiliary phase is not optimized, and also that the speed loop has not been used so far. To provide the same value of phase current and consequently torque in both main and auxiliary phases is necessary to boost the voltage of auxiliary phase.

\section{CONCLUSIONS}

The novel supply system for two phase induction motor has been introduced. The system comprises just single leg of matrix converter, and features by reduced number of active and passive components of the converter. The simulation results agree with the theoretical expectations, that the single leg of matrix converter is able to create sinusoidal current waveforms on output side, which is necessary for good working condition of drive systems. One problem is still open - variable capacitance of capacitor in auxiliary phase of the motor. Practical solution leads to switched capacitors; for small power single phase drive is possible operation with fixed run capacitor. From the economic point of it would be nice to use monolithic bidirectional switches which development has been announced based on Mosfet structures. Future work is oriented to investigation of the system in closed speed loop operation, decreasing of torque ripple, optimizing of capacitor value, and efficiency investigation.

\section{REFERENCES}

[1] A. Zuckerberger, D. Weinstock, A. Alexandrovitz, "Single-phase matrix converter", in IEE Proc. on Electric Power App., vol. 144, no. 4, 1997, pp. 235-240. [Online]. Available: http://dx.doi.org/ 10.1049/ip-epa:19970848

[2] B. Dobrucky, R. Havrila, J. Dubovsky, "A single-phase supplied matrix converter with unity power factor", in Proc. of Int'l Conf. (EPE-PEMC), Prague, 1998, pp. 146-150.

[3] P. Wheeler, J. Rodriguez, J. Clare, L. Empringham, A. Weinstein, "Matrix converters: a technology review", Industrial Electronics, IEEE Trans., vol. 49, no. 2, pp. 276-288, 2002. [Online]. Available: http://dx.doi.org/10.1109/41.993260
[4] S. Jeevananthan, P. Dananjayan, R. Madhavan, "Novel single-phase to single-phase cyclo-conversion strategies: mathematical and simulations studies", Int'l Journal of Power and Energy Systems, vol. 27, no. 4, pp. 414-423, 2004.

[5] M. Prazenica, B. Dobrucky, "Orthogonal electronic system with twostage two-phase connection using two single-phase matrix converters in half-bridge connection", in Proc. of Int'l Conf. on Applied Electronics, Pilsen, 2010, pp. 281-284.

[6] B. Dobrucky, P. Spanik, M. Kabasta, "Power electronic two-phase orthogonal system with HF input and variable output", Elektronika ir Elektrotechnika, vol. 1, pp. 9-14, 2009.

[7] B. Dobrucky, M. Marcokova, M. Kabasta, "Using orthogonal transform for solution of matrix converter power circumstances in Mathematica (® environment", in Proc. of 7th Int'l Conf. on Applied Mathematics (APLIMAT 2008), Bratislava, 2008. pp. 735-739.

[8] P. Chlebis, P. Simonik, M. Kabasta, "The comparison of direct and indirect matrix converters", in Proc. Int'l Conf. (PIERS), Cambridge, USA, 2010, pp. 310-313.

[9] F. Iov, F. Blaabjerg, R. Basset, J. Clare, A. Rufer, S. Savio, P. Biller, P. Taylor, B. Snayers, "Advanced power converter for universal and flexible power management in future electricity network", in Proc. Int'l Conf. on Electricity Distribution (CIRED 2007), Vienna (AT), 2007, paper No 0217, pp. P. 1-P. 4.

[10] M. Popescu, E. Demeter, D. Micu, V. Navrapescu, T. Jokinen, "Analysis of a voltage regulator for a two-phase induction motor drive", in Proc. Int'l Conf. on Electric Machines and Drives (IEMD), Seattle (USA), 1999, pp. 658-660. [Online]. Available: http://dx.doi.org/10.1109/iemdc.1999.769205

[11] M. Chomat, T. A. Lipo, "Adjustable-speed single-phase IM drive with reduced number of switches", in Conf. Rec. Annu. Meeting (IEEEIAS), 2001, pp. 1800-1806. [Online]. Available: http://dx.doi.org/ 10.1109/ias.2001.955776

[12] M. Chomat, T. A. Lipo, "Adjustable-speed drive with single-phase induction machine for HVAC applications", in Proc. (IEEE PESC 2001), 2001, pp. 1446-1451.

[13] M. Chomat, T. Lipo, "Adjustable-speed single-phase IM drive with reduced number of switches", IEEE Trans. Industry Applications, vol. 39, no. 3, pp. 819-825, 2003. [Online]. Available: http://dx.doi.org/10.1109/TIA.2003.811778

[14] J. Klima, "Analytical model of induction motor fed from four-switch space vector PWM inverter. Time domain analysis", Acta Technica CSAV, vol. 44, pp. 393-410, 1999.

[15] MathWorks, "Single Phase Asynchronous Machine", [Online] Available: http:// www.mathworks.se/help/physmod/sps/powersys/ref/singlephaseasync hronousmachine.html

[16] E. R. Benedict, T. A. Lipo, "Improved PWM modulation for a permanent-split capacitor motor", in Conf. Rec. Annu. Meeting (IEEE$I A S)$, 2000, pp. 2004-2010. [Online]. Available: http://dx.doi.org/ 10.1109/ias.2000.882152

[17] A. Lettenmainer, D. Novotny, T. A. Lipo, "Single-phase induction motor with an electronically controlled capacitor", IEEE Trans. Industry Applications, vol. 27, no. 1, 1988, pp. 38-43. [Online] Available: http://dx.doi.org/10.1109/28.67530

[18] T. H. Liu, Y. Zhao, T. A. Lipo, E. Muljadi, "Adjustable AC capacitor for a single-phase induction motor", IEEE Trans. Industry Applications, vol. 29, no. 3, 1993, pp. 479-485. [Online]. Available: http://dx.doi.org/10.1109/28.222415

[19] C. Suciu, M. Kansara, P. Holmes, W. Szabo, "Performance enhancement of an induction motor by secondary impedance control", IEEE Trans. Energy Conversion, vol. 17, no. 2, pp. 211-216, 2002. [Online]. Available: http://dx.doi.org/10.1109/TEC.2002.1009470

[20] A. Danila, I. Margineanu, R. Campeanu, C. Suciu, I. Boian, "The optimization of the single-two phase induction motor start-up with electronically switched capacitor", in Proc. of IEEE Int'l Conf. on Automation, Quality and Testing, Robotics, (AQTR 2008), ClujNapoca, 2008, vol. 3, pp. 450-453. [Online]. Available: http://dx.doi.org/10.1109/aqtr.2008.4588962

[21] S. Sunter, M. Ozdemir, B. Gumus, "Modelling and simulation of single phase induction motor with adjustable switched capacitor", in Proc. of 9th Int'l Conf. on Power Electronic and Motion Control (EPE-PEMC 2000), Kosice, 2000, pp. 5-1-5-5.

[22] V. Vodovozov, N. Lillo, Z. Raud, "Single-phase electric drive for automotive applications", in Proc. of Int'l Symp. on Power Electronics, Electrical Drives, Automation and Motion (SPEEDAM 2014), Ischia, 2014, pp. 1293-1298. [Online]. Available: http://dx.doi.org/10.1109/speedam.2014.6872106 